Leading Article

\title{
A new look at digoxin in congestive heart failure and sinus rhythm
}

\author{
Adam D. Timmis
}

London Chest and Newham General Hospitals, London, UK.

The role of cardiac glycosides in the treatment of congestive heart failure is controversial. ${ }^{1}$ Digoxin is the most widely used compound particularly for the patient in atrial fibrillation where it remains the drug of choice for controlling the ventricular rate. For the patient in sinus rhythm, however, there is no firm consensus and opinions range from the almost nihilistic which see no role at all for digoxin to the opposite extreme which see it as first line treatment. There is no doubt that this controversy reflects the paucity of randomized clinical trials and the recent publication of three major studies, ${ }^{2-4}$ therefore, is timely because it is now more than 200 years since Withering's Account of the Foxglove first appeared. ${ }^{5}$

In congestive heart failure myocardial contractility is depressed because the binding of calcium by the sarcoplasmic reticulum and its delivery to the contractile proteins is impaired. Cardiac glycosides inhibit the membrane sodium-potassium pump raising the concentration of intracellular sodium which is then available for exchange with extracellular calcium by another membrane transport system. ${ }^{6}$ Thus cardiac glycosides can increase intracellular calcium and enhance contractility. The clinical importance of this mechanism, however, has been uncertain because the increase in intracellular sodium available for calcium exchange is almost vanishingly small. Nevertheless, experiments using intracellular microelectrodes have confirmed small, dose-dependent increases in sodium and a simultaneous inotropic response following exposure to cardiac glycosides. Indeed, an increase in intracellular sodium of only $1 \mathrm{mM}$ is sufficient to double the strength of contraction. ${ }^{7,8}$

Cardiac glycosides also have important effects on the cardiac conducting tissue and the peripheral circulation. ${ }^{9}$ They slow conduction through the atrioventricular node by increasing both the vagal tone and the sensitivity of the node to vagal effects.

Correspondence: Adam D. Timmis M.D., M.R.C.P. Department of Cardiology, London Chest Hospital, Bonner Road, London E2 9JX, UK.

Received: 8 May 1989
Peripheral vascular responses to cardiac glycosides are complex. There is a direct vasoconstrictor effect and also a neurogenic vasodilator effect which acts through sensitization of the carotid baroreceptors. ${ }^{10,11}$ Clinically, the vasoconstrictor action dominates and when heart failure is severe enough to produce cardiogenic shock the increase in afterload may offset any potential benefit of inotropic stimulation. ${ }^{12}$

The inotropic action of cardiac glycosides has been confirmed in muscle bath experiments ${ }^{13}$ and also in the normal human heart..$^{14}$ In the failing heart, however, it has been more difficult to demonstrate a useful inotropic response..$^{15}$ Early studies described the effects of digoxin withdrawal with inconsistent results, some investigators reporting significant clinical deterioration, ${ }^{16}$ others reporting no palpable change. ${ }^{17}$ Similar inconsistency has characterized the results of placebo-controlled cross-over studies in patients in sinus rhythm. Thus, Dobbs et al..$^{18}$ found that 16 of 46 heart failure patients deteriorated on placebo and 8 completely recovered when digoxin was reintroduced. Fleg et al. ${ }^{19}$ on the other hand, detected no digitalisinduced clinical benefit in a similar study while Lee $e t$ $a l .^{20}$ found that appreciable clinical improvement was restricted to patients with severe heart failure and a gallop rhythm. Based on these results it is hardly surprising that cardiologists in this country and elsewhere have been unable to agree upon indications for digoxin therapy for the patient in sinus rhythm.

We now have data from three large randomized studies which suggest a potentially useful role for digoxin in congestive heart failure and sinus rhythm. The Captopril-Digitalis Research Group ${ }^{2}$ randomized 300 patients on frusemide therapy to additional treatment with digoxin, captopril or placebo. Only digoxin produced a significant improvement in left ventricular function (as judged by ejection fraction) although this was not associated with a significant improvement in exercise tolerance. Interestingly (and conversely), captopril improved exercise tolerance without affecting left ventricular ejection fraction. The same year, the German and Austrian Xamoterol Study Group ${ }^{3}$ reported a trial in which 433 
patients were randomized to receive placebo, xamoterol or digoxin in the ratio 1:2:1. It is important to emphasize that these patients had only mild to moderate heart failure and less than $20 \%$ of the patients were on diuretics. Nevertheless, digoxin produced significant improvement in dyspnoea and oedema associated with a $17 \%$ (statistically insignificant) improvement in exercise tolerance. Responses to xamoterol (a new beta 1 partial agonist) were similar although the $34 \%$ improvement in exercise tolerance was significant, possibly because the larger numbers randomized to this drug prevented a type 2 statistical error. Most recently, the Milrinone Multicenter Trial Group ${ }^{4}$ reported the results of a trial in which 230 patients in sinus rhythm with moderately severe heart failure (all on diuretics) were randomized to treatment with digoxin, milrinone, both or placebo. After 3 months, digoxin improved left ventricular function (as judged by ejection fraction) and this was associated with a significant increase in exercise tolerance. Moreover, the frequency of decompensation from heart failure fell from $47 \%$ with placebo to $15 \%$ with digoxin. Results with milrinone (a new phosphodiesterase inhibitor) were broadly similar.

These data confirm that digoxin improves left ventricular function in congestive heart failure and sinus rhythm and leads to variable clinical improvement which is most marked when heart failure is severe. At present patients with severe heart failure are usually treated with diuretics and angiotensin converting enzyme (ACE) inhibitors but recent work has shown that further improvement in resting and exercise haemodynamics can be achieved by the addition of digoxin..$^{21,22}$ Thus a reasonable policy would be to reserve digoxin for patients in sinus rhythm in whom

\section{References}

1. Chamberlain, D.A. Digitalis: where are we now? $\mathrm{Br}$ Heart J 1985, 54: 227-233.

2. Captopril-Digoxin Multicenter Research Group. Comparative effects of therapy with captopril and digoxin in patients with mild to moderate heart failure. JAMA 1988, 259: 539-544.

3. The German and Austrian Xamoterol Study Group. Double-blind placebo-controlled comparison of digoxin and xamoterol in chronic heart failure. Lancet 1988, i: 489-493.

4. DiBianco, R., Shabetai, R., Kostuk, W., Moran, J., Schlant, R.C. \& Wright, R. For the Milrinone Multicenter Trial Group. A comparison of oral milrinone, digoxin and their combination in the treatment of patients with chronic heart failure. N Engl J Med 1989, 320: 677-683.

5. Withering, W. An Account of the Foxglove, and Some of its Medical Uses: With Practical Remarks on Dropsy and other Diseases. M Swinney, Birmingham, England, 1785. the response to diuretics and ACE inhibitors is unsatisfactory. In patients of this type digoxin can be $\stackrel{\varnothing}{\varnothing}$ expected to produce a useful improvement in both left $\stackrel{.}{.}$ ventricular function and exercise capacity.

Concern is often expressed about the narrow $\frac{0}{0}$ therapeutic range of digoxin and the risks of toxicity. ${ }^{23} \frac{\mathrm{C}}{\mathrm{O}}$ However, in the recent randomized trials digoxin was $\frac{\overline{\bar{S}}}{\overline{\mathrm{T}}}$ remarkably well tolerated and in none of them were $\vec{\nabla}$

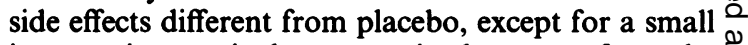
increase in ventricular ectopy in the report from the $\$$ Captopril-Digitalis Research Group. Nevertheless, $\vec{\circ}$ there remains some concern about the long-term $\overrightarrow{-}$ effects of inotropic stimulation in general and digoxin $\vec{\sigma}$ in particular. ${ }^{24}$ Bigger et al. ${ }^{25}$ in a review of pooled data $\frac{\partial}{\partial}$ from four acute infarction studies concluded that there $\frac{0}{3}$ was a persistent risk associated with digoxin which could not be explained by baseline differences between $N$ treatment groups. The MILIS investigators, ${ }^{26}$ on the ${ }^{\circ}$ other hand, were able to attribute the excess mortality in patients treated with digoxin to the severity of $\vec{G}$ infarction. None of the recent trials has identified an $\mathrm{O}$ increased risk of death in patients randomized to digoxin and although long-term data are not available $\bigcirc$ it seems unlikely that a drug which has been widely $\frac{\Upsilon}{0}$ used for more than 200 years would be the cause 요음 significant excess mortality.

At present digoxin is the only orally active inotrop $\overrightarrow{0}$ agent licensed for use in congestive heart failure. primary indication is for rate control in atrial fibrills tion but, based on the results of recent randomized trials, it is now clear that many patients in sinus rhythm will also benefit from treatment with digoxin, particularly those with advanced heart failure in $\mathbb{D}$ whom the reponse to diuretics and ACE inhibitors is inadequate.
6. Fozzard, H.A. \& Sheets, M.F. Cellular mechanism of action of cardiac glycosides. J Am Coll Cardiol 1985, 5: 10A-15A.

7. Ellis, $D$. The effects of external cations and ouabain on the intracellular sodium activity of the sheep heart Purkinje fibres. J Physiol 1977, 273: 211-240.

8. Wasserstrom, J.A., Schwartz, D.J. \& Fozzard, H.A. Relation between intracellular sodium and twitch tension in sheep cardiac Purkinje strands exposed to cardiac $\sigma$ glycosides. Circ Res 1983, 52: 697-705.

9. Watanabe, A.M. Digitalis and the autonomic nervous system. J Am Coll Cardiol 1985, 5: 35A-42A.

10. Ferrari, A., Gregorini, L., Ferrari, M.L., Preti, L. \& Mancia, G. Digitalis and baroreceptor reflexes. Circulation 1981, 63: 279-285.

11. Lopez, J.A., Timmis, A.D., Garan, H., Homcy, C.J. ? Powell, W.J.Jr. The effect of the intracarotid administra- $\square$ tion of ouabain in the dog. Am J Physiol 1988, 254: H148-H155. 
12. Cohn, J.N., Tristani, F.E. \& Khatri, I.M. Cardiac and peripheral vascular effects of digitalis in clinical cardiogenic shock. Am Heart $J$ 1969, 78: 318-330.

13. Gold, H. \& Cattell, M. Mechanisms of digitalis action in abolishing heart failure. Arch Intern Med 1940, 65: 263-278.

14. Sonnenblick, E.H., Williams, J.F. Jr, Glick, G., Mason, D.T. \& Braunwald, E. Studies on cardiac glycosides. XV. Effects of cardiac glycosides on myocardial force velocity relations in the nonfailing human heart. Circulation 1966, 34: 532-539.

15. Kleiman, J.H., Alderman, E.L. \& Goldman, R.H. Effects of digitalis on normal and abnormal left ventricular segmental dynamics. Am J Cardiol 1979, 43: $1001-1008$.

16. Arnold, S.B., Byrd, R.C. \& Meister, W. Long-term digitalis therapy improves left ventricular function in heart failure. N Engl J Med 1980, 303: 1443-1448.

17. Mulrow, C.D., Feussner, J.R. \& Velez, R. Reevaluation of digitalis efficacy. New light on an old leaf. Ann Intern Med 1984, 101: 113-117.

18. Dobbs, S.M., Kenyon, W.I. \& Dobbs, R.J. Maintenance digoxin after an episode of heart failure: placebocontrolled trial in outpatients. $B r$ Med $J$ 1977, 1: 749-751.

19. Fleg, J.L., Gottlieb, S.H. \& Lakatta, E.G. Is digoxin really important in treatment of compensated heart failure? A placebo-controlled cross-over study in patients in sinus rhythm. Am J Med 1983, 73: 244-250.
20. Lee, D.C., Johnson, R.A. \& Bingham, J.B. Heart failure in outpatients: a randomized trial of digoxin versus placebo. $N$ Engl J Med 1982, 306: 699-705.

21. Gheorghiade, M., St Clair, J., St Clair, C. \& Beller, G.A. Hemodynamic effects of intravenous digoxin in patients with severe heart failure initially treated with diuretics and vasodilators. J Am Coll Cardiol 1987, 9: 849-857.

22. Gheorghiade, M., Hall, V., Lakier, J.B. \& Goldstein, S. Comparative hemodynamic and neurohumoral effects of intravenous captopril and digoxin and their combinations in patients with severe heart failure. J Am Coll Cardiol 1989, 13: 134-142.

23. Timmis, A.D. Modern treatment of heart failure. $\mathrm{Br} \mathrm{Med}$ J 1988, 297: 83-84.

24. Katz, A.M. Potential deleterious effects of inotropic agents in the therapy of chronic heart failure. Circulation 1986, 73: (suppl 111): 184-188.

25. Bigger, J.T., Fleiss, J.L., Rolnitzky, L.M., Merab, J.P. \& Ferrick, K.L. Effect of digitalis treatment on survival after acute myocardial infarction. Am J Cardiol 1985, 55: 623-630.

26. Muller, J.E., Turi, Z.G., Stone, P.H. et al. Digoxin therapy and mortality after myocardial infarction. Experience in the MILIS study. $N$ Engl J Med 1986, 314: 265-271. 